\title{
FAKTOR-FAKTOR PEMILIHAN PERBANKAN \\ SYARIAH DAN KONVENSIONAL BERBASIS FLOATING MARKET \\ DI PANGKAL PINANG BANGKA BELITUNG
}

\author{
Marheni \\ Dosen Fakultas Syariah dan Ekonomi Islam \\ IAIN SAS Bangka Belitung \\ marheni.utama@gmail.com
}

\begin{abstract}
Abstrak
Tujuan penelitian ini adalah mendeskripsikan karakteristik nasabah berdasarkan floating market; mengetahui faktor-faktor yang mempengaruhi keputusan nasabah dalam memilih bank syari'ah berdasarkan sifat pribadi dan sosial di Pangkal Pinang Bangka Belitung. Jenis penelitian ini adalah explanatary research. Populasi dan sampel adalah 100 responden di wilayah Pangkalpinang. Metode alat analisis data menggunakan alat analisis regresi logistik. Hasil pengujian menunjukkan setiap perbedaan gender maka tidak berpengaruh terhadap keputusan memilih bank syari'ah dan bank konvensional. Faktor usia berpengaruh terhadap keputusan memilih bank syari'ah dan bank konvensional. Status pekerjaan tidak berpengaruh terhadap keputusan memilih bank syari'ah dan bank konvensional. Sifat pribadi berpengaruh negatif dan signifikan terhadap keputusan memilih bank syari'ah dan bank konvensional. Variabel sistem sosial tidak berpengaruh terhadap keputusan memilih bank syari'ah dan bank konvensional.
\end{abstract}

Kata Kunci : karakteristik nasabah, jenis kelamin, sifat pribadi, sistem sosial dan floating market

\section{ABSTRACT}

This aims of study were to describe the characteristics of customers based on the floating market; find out the factors that influence the customer's decision in choosing a Shariah bank based on personal and social nature in Pangkal Pinang Bangka Belitung. This type of research was explanatary research. The population and sample were 100 respondents in the Pangkalpinang region. Methods of data analysis tools used logistic regression analysis tools. The test results showed that every gender difference did not affect the decision to choose a sharia bank and conventional bank. The age factor influences the decision to choose a sharia bank and conventional bank. Job status did not affect the decision to choose a Shariah bank and a conventional bank. Personal characteristics had a negative and significant effect on the decision to choose a sharia bank and conventional bank. Social system variables did not affect the decision to choose a sharia bank and a conventional bank. 


\section{Jurnal Ilmiah Sustainable}

Vo. 1. No. 1, Juni 2018, 114-134

Keywords: customer characteristics, gender, personal nature, social system and floating market

\section{A. Pendahuluan}

Tantangan yang dihadapi bank syari'ah yang dihadapi dikarenakan bank syari'ah sebagai bank konvensional yang berlabel Islami. Selain itu, ciri khas bank syari'ah dapat ditonjolkan dengan adanya ciri khas syari'ah dengan membangun sektor riil dengan prinsip keadilan. Tantangan dari masyarakat yang masih memiliki pemahaman yang kurang tentang operasional bank syari'ah serta pihak perbankan yang menganggap bahwa operasional bank tidak akan berjalan jika tidak ada pendapatan yang berasal dari bunga. Hal ini menyebabkan bank tidak akan dapat berlangsung atau bertahan dalam persaingan. Peran bank syari'ah di Indonesia diatur dalam sistem perbankan syari'ah yang diatur dalam UndangUndang Nomor 10 tahun 1998 tentang perbankan, dimana bank umum adalah bank yang melaksanakan kegiatan usaha secara konvensional atau berdasarkan prinsip syari'ah yang kegiatannya memberikan jasa dalam lalu lintas pembayaran.

Pertumbuhan perekonomian daerah dapat meningkat dengan adanya peran bank syari'ah karena dijadikan strategi yang menyeimbangkan struktur perekonomian. Sistem terbaru adanya "dual banking system", dimana bank konvensional diperkenankan untuk membuka unit usaha syari'ah. Meskipun masyarakat di Indonesia yang mayoritas adalah beragama Islam tetapi perkembangan bank syari'ah tidak secepat bank konvensional. Hal itu dikarenakan usaha untuk mengembangkan bank syari'ah bukan hanya berdasarkan legalitas hukum dan perundang-undangan tetapi juga segmen pasar dan masyarakat yang akan menjadi pengguna bank syari'ah. Adanya bank syari'ah dan konvensional berfungsi strategis untuk menjadi lembaga intermediasi dalam lalu lintas pembayaran. Adanya perbedaan tipe bank tersebut membuat perilaku nasabah dalam memilih bank dapat dipengaruhi oleh sikap dan persepsi masyarakat terhadap karakteristik perbankan itu sendiri. ${ }^{1}$

Lembaga keuangan bank syari'ah dikenal dengan sistem bagi hasil. Bank syari'ah memiliki konsep pembagian hasil usaha antara pemilik modal dengan

\footnotetext{
1 Yusdani. 2005. Perbankan Syariah Berbasis Floating Market. Millah Vol. IV, No. 2.
} 


\section{Jurnal Ilmiah Sustainable}

Vo. 1. No. 1, Juni 2018, 114-134

pihak pengelola modal. Pengelolaan bank dengan prinsip syari'ah dapat diakses dan dikelola oleh seluruh masyarakat yang berminat tidak terbatas pada masyarakat yang beragama Islam saja meskipun sampai saat ini bank syari'ah masih diminati oleh masyarakat muslim. Peluang bank syari'ah di Indonesia termausk tinggi karena kaum mayoritas adalah muslim. Bank syari'ah membutuhkan strategi baru dalam mengembangkan usahanya di Indonesia, dengan mempertimbangkan pasar masyarakat muslim (spiritual market) dan masyarakat yang memilih keduanya floating market ${ }^{2}$. Perbankan syari'ah telah menunjukkan kinerja keuangan yang lebih baik secara sistem perbankan, namun sistem perbankan syari'ah sementara ini memberikan keuntungan yang rendah dibandingkan perbankan konvensional ${ }^{3}$. Oleh karena itu strategi floating market diperlukan dalam sistem perbankan syari'ah melalui efisiensi internal dan menerapkan strategi ekspansi economics of scale dan economic of scope.

Adanya kebijakan dual banking system pada tahun 1992 belum bisa berjalan optimal karena pangsa pasar bank syari'ah belum signifikan yaitu 6,25\% pada Oktober $2015^{4}$. Strategi pengelolaan bank syari'ah difokuskan nasabah muslim dan non muslim. ${ }^{5}$ Hal yang menjadi pertimbangan dengan keberadaan masyarakat non muslim di beberapa wilayah menjadi target pasar. Strategi pengembangan bank syari'ah difokuskan pada pasar yang berpotensi yaitu potensi masyarakat non muslim. Alasan startegi tersebut dilaksanakan antara lain 1) larangan pemungutan riba, yang merupakan ciri utama bank syari'ah, ternyata memiliki akar pada ajaran-ajaran non muslim; 2) keseluruhan kinerja perbankan syari'ah lebih baik dengan perbankan konvensional; 3) tidak ada perbedaan preferensi yang signifikan dalam pemilihan bank oleh nasabah muslim maupun non muslim.

Perbankan syari'ah perlu memeprhatikan kualitas layanan dalam menyajikan model baru dengan menambah satu dimensi "Compliance with Islamic Law" pada model kualitas pelayanan "SERVQUAL" yang dikenal dengan system CARTER meliputi Compliance, Assurance, Reliability, Tangible, Empathy, and Responsiveness. Hal ini akan menimbulkan kepuasan pelanggan dalam

\section{Ibid}

${ }^{3}$ Ghafur, Muhammad. 2007. Potret Perbankan Syariah Terkini (Kajian Kritis Perkembangan Perbankan Syariah). Yogyakarta: Biruni Press.

${ }^{4}$ Bank Indonesia. 2015. Outlook Perbankan Syariah 2015.

${ }^{5}$ Op.cit. Yusdani. 2005. 


\section{Jurnal Ilmiah Sustainable}

\section{Vo. 1. No. 1, Juni 2018, 114-134}

menggunakan jasa bank syari'ah sehingga tercipta hubungan hubungan antara kualitas layanan dengan kepuasan pelanggan dengan suatu system CARTER sebagai items proses input dan outputnya overall satisfaction. ${ }^{6}$

Bank Indonesia melakukan penelitian dengan bekerjasama dengan beberapa lembaga penelitian untuk memetakan potensi pengembangan Bank Syari'ah yang didasarkan pada analisis potensi ekonomi dan pola sikap/preferensi dari pelaku ekonomi dan jasa bank syari'ah. Penelitian ini juga meneliti tentang karakteristik dan perilaku nasabah dan calon nasabah bank syari'ah untuk menetapkan strategi sosialisasi dan pemasaran bagi bank syari'ah. Lokais penelitian dilakukan di pulau Jawa yaitu Jawa Barat, Jawa Tengah/ DIY dan Jawa Timur ${ }^{7}$. Hasil penelitian menemukan jawaban responden tentang sistem perbankan penting dan dibutuhkan dalam mendukung kelancaran transaksi ekonomi sebanyak 95\%. Hal pokok yang menjadi haisl penelitian antara lain sistem bagi hasil bank syari'ah, bank syari'ah hanya untuk masyarakat muslim dengan hasil survey di Jawa Barat $81 \%$ menyatakan bahwa bank syari'ah hanya untukpengguna beragama muslim. Hasil penelitian juga menemukan bahwa pengetahuan masyarakat tentang sistem perbankan syari'ah relatif tinggi. Meskipun demikian pemahaman mengenai keunikan produk/jasa Bank Syari'ah secara umum masih rendah ${ }^{8}$.

Paul Wouters ${ }^{9}$ meneliti tentang bank syari'ah di Turki, Indonesia, Pakistan dan Malayasia. Hasil penelitian menunjukkan bahwa masyarakat Indonesia lebih tertarik terhadap bank syari'ah dibandingkan ketiga negara. Yaumidin, Umi Karomah ${ }^{10}$ menemukan bahwa bank-bank Islam di Asia Tenggara sedikit lebih efisien dibandingkan bank-bank Islam di Timur Tengah dan tergantung pada sistem keuangan dan segala bentuk peraturan perbankan.

Anggapan masyarakat tentang bank syari'ah dengan nilai tambah bank syari'ah adalah halal dan sesuai aturan agama Islam dalam transaksinya, ada

${ }^{6}$ Othman, Abdul Qawi dan Lynn Owen. 2008. Adopting and Measuring Customer Service Quality (SQ) In Islamics Banks : A Case Study In Kuwait Finance House. International Journal of Islamic Financial Services, Vol 3, No.1, page 1-26.

${ }^{7}$ Astutik, Rini Puji.2015. Faktor-faktor Pemilihan Bank Syariah. Jurnal Universitas Muhammadyah Jember. Vol. 5.No.2

8 lbid, hal. 8

${ }^{9}$ Wouters, Paul.2016. Islamic Banking In Turkey, Indonesia And Pakistan A Comparison With Malaysia. www.iefpedia.com. Tanggal akses 2 Agustus 2018

${ }^{10}$ Op.Cit. Abdul Qawi Othman dan Lynn Owen 


\section{Jurnal Ilmiah Sustainable}

Vo. 1. No. 1, Juni 2018, 114-134

kebaikan akhirat, dan menolong antar sesama dibandingkan dengan bank konvensional. Tetapi bank syari'ah memiliki keuntungan karena produkproduknya tidak kalah bersaing dengan bank konvensional dan sistem bagi hasil yang ditawarkan tidak kalah menguntungkan dibandingkan dengan bunga. Pemahaman masyarakat yang masih rendah tentang bank syari'ah maka perbankan syari'ah harus terus berkembang dan memperbaiki kinerjanya. Pertumbuhan yang pesat dengan unit-unit syari'ah yang didirikan bank konvensional membuktikan bahwa bank syari'ah memiliki kompetensi yang tinggi. Pertumbuhan perbankan syari'ah semakin tinggi jika masyarakat mempunyai permintaan dan antusias yang tinggi dikarenakan faktor peningkatan pemahaman dan pengetahuan tentang bank syari'ah.

Penelitian ini dilakukan di wilayah Bangka Belitung yang mayoritas beragama Islam. Bangka Belitung juga memiliki peluang pasar yang menguntungkan dengan berbagai variasi masyarakat termasuk non muslim dengan membidik floating market. Penelitian ini bertujuan mendeskripsikan karakteristik nasabah berdasarkan floating market; mengetahui faktor-faktor yang mempengaruhi keputusan nasabah dalam memilih bank syari'ah atau bank konvensional di Pangkal Pinang Bangka Belitung.

\section{B. Kerangka Teori}

\section{Pengertian Bank Syariah}

Bank Syariah menurut Undang-undang No. 10 tahun 1998 adalah Bank umum yang melaksanakan usaha berdasarkan prinsip syari'ah yang dalam kegiatannya memberikan jasa dalam lalu lintas pembayaran. Prinsip syari'ah adalah aturan perjanjian berdasarkan hukum Islam antara bank dengan pihak lain untuk penyimpanan dana dan atau pembiayaan kegiatan usaha atau kegiatan lainnya yang sesuai dengan syari'ah. ${ }^{11}$

Prinsip yang dijalankan bank syari'ah dalam menjalankan operasionalnya adalah: ${ }^{12}$

1. Prinsip keadilan yang diterapkan dengan imbalan atas dasar bagi hasil dan pengambilan margin keuntungan yang telah disepakati oleh bank dan nasabah.

\footnotetext{
${ }^{11}$ Undang-Undang Nomor 10 Tahun 1998 Tentang Perbankan.

${ }^{12}$ Rivai, Veithzal dan Arviyan Arifin. 2010. Islamic Banking: sebuah teori, konsep, dan aplikasi. Jakarta: Bumi Aksara.
} 


\section{Jurnal Ilmiah Sustainable}

\section{Vo. 1. No. 1, Juni 2018, 114-134}

2. Prinsip kesederajatan dengan penempatan nasabah penyimpan dana, nasabah pengguna dana, maupun bank pada kedudukan yang sama dan sederajat dalam bank syari'ah. Hal ini tercermin dalam hak, kewajiban, resiko, dan keuntungan yang berimbang di antara nasabah penyimpan dana, nasabah pengguna dana, maupun pihak bank.

3. Prinsip ketenteraman yaitu adanya kesesuian dengan prinsip dan kaidah Islam muamalah dari produk-produk bank syari'ah yaitu tidak ada unsur riba dan menerapkan zakat harta sehingga nasabah merasakan ketenteraman lahir dan batin.

Adopsi perbankan syari'ah dalam sistem perbankan nasional tidak hanya mementingkan kepentingan penduduk Indonesia yang mayoritas sebagian besar beragama Islam, namun lebih kepada adanya faktor keunggulan atau manfaat lebih dari perbankan syari'ah dalam peranan perekonomian. Sistem perbankan konvensional merupakan wadah yang menghubungkan antara pemilik dana dan dunia usaha, perbankan juga masih menjadi penyekat antara keduanya karena tidak adanya transferability risk and return. Sistem perbankan syari'ah dimana perbankan syari'ah menjadi manajer investasi, wakil, atau pemegang amanat dari pemilik dana atas investasi di sektor riil. Seluruh keberhasilan dan resiko dunia usaha secara langsung didistribusikan kepada pemilik dana.

Bank syari'ah secara prinsip memiliki tantangan, namun dalam realitasnya bank syari'ah, menghadapi beberapa kendala dan kelemahan yang memerlukan pembenahan yaitu jaringan operasi yang belum luas, institusi pendukung yang belum lengkap dan efektif, efisiensi operasional bank syari'ah yang belum optimal dan masih sedikitnya sumber daya manusia yang memiliki keahlian dalam perbankan syari'ah. Berdasarkan sisi konsumen, kelemahan yang dihadapi bank syari'ah pemahaman masyarakat yang masih rendah mengenai kegiatan usaha jasa keuangan perbankan syari'ah sehingga menyebabkan masyarakat memiliki persepsi yang kurang tepat mengenai operasi bank syari'ah.

\section{Pengembangan Bank Syariah Berbasis Floating Market}

Selama ini kalangan perbankan syari'ah umumnya masih memfokuskan sasaran pada para loyalis syari'ah atau pasar fanatik terhadap syari'ah. ${ }^{13}$ Tetapi bank syari'ah belum menangkap pasar pengambang (floating market) atau pasar yang tidak terlalu fanatik terhadap suatu sistem perbankan, konvensional atau syari'ah. Segmen pasar ini tergantung sistem mana yang paling menguntungkan

\footnotetext{
${ }^{13}$ Op.cit. Yusdiani. 2005.
} 


\section{Jurnal Ilmiah Sustainable}

Vo. 1. No. 1, Juni 2018, 114-134

dalam memutuskan menggunakan jasa perbankan. Perbankan syari'ah perlu memberikan perhatian kepada non muslim seperti Yahudi dan Kristen pun juga memiliki akar yang kuat mengenai larangan pemungutan riba.

Selain itu dalam berbagai kategori penting, kinerja perbankan syari'ah ternyata relatif lebih baik dan efisien dibandingkan bank konvensional. Hal ini terungkap dalam penelitian yang dilakukan Ascarya (2008) ${ }^{14}$ dari pusat Penelitian dan Studi Kebanksentralan Bank Indonesia (PPSK BI). Sasaran pasar rasional dan non muslim dengan mempertahankan perhatian kepada umat muslim sebagai dasar spiritual yang utama, diharapkan dapat meningkatkan kinerja perbankan syari'ah lebih baik lagi dalam memberikan pelayanan kepada para nasabahnya. Berbagai penelitian terdahulu yang telah dilakukan dijelaskan berikut.

\section{Tabel 1}

Penelitian Terdahulu

\begin{tabular}{|c|c|c|c|}
\hline Nama & Idul & $\begin{array}{c}\text { Variabel dan Alat } \\
\text { Analisis }\end{array}$ & Hasil \\
\hline $\begin{array}{c}\text { dan } \\
005)^{15}\end{array}$ & $\begin{array}{l}\text { Islamic } \\
\text { Banking } \\
\text { Consumer } \\
\text { Behaviour } \\
\text { in Indonesia: A } \\
\text { Qualitative } \\
\text { Approach }\end{array}$ & $\begin{array}{l}\text { Motivasi dan } \\
\text { keputusan } \\
\text { konsumen } \\
\text { Metode : Kualitatif } \\
\text { dengan metode } \\
\text { deduktif }\end{array}$ & $\begin{array}{lr}\text { Model K } & \text { Mark } \\
\text { sgemnetation } & \\
\text { menunjukkan } & \text { adanya } \\
\text { perbedaan } & \text { segmen } \\
\text { bank Islami } & \text { dalam } \\
\text { keputusan } & \text { nasabah } \\
\text { memilih bank syari'ah. }\end{array}$ \\
\hline $\begin{array}{l}\text { Abdul Qawi } \\
\text { Othman dan } \\
\text { Lynn Owen } \\
(2007)^{16}\end{array}$ & $\begin{array}{l}\text { Adopting and } \\
\text { Measuring } \\
\text { Customer } \\
\text { Service Quality } \\
\text { (SQ) In Iskamic } \\
\text { Banks: A Case } \\
\text { Study In }\end{array}$ & $\begin{array}{l}\text { CARTER-items } \\
\text { (Compliance, } \\
\text { Assurance, } \\
\text { Reliability, } \\
\text { Tangible, Emphaty, } \\
\text { dan } \\
\text { responsiveness), }\end{array}$ & $\begin{array}{l}\text { Model dalam mengukur } \\
\text { kualitas layanan dengan } \\
\text { CARTER-item yang } \\
\text { didasarkan pada } 34 \\
\text { variabel berdasarkan } \\
\text { budaya dalam } \\
\text { pemilihan bank Islam }\end{array}$ \\
\hline
\end{tabular}

${ }^{14}$ Yumanita, Ascaraya Diana. 2008. Comparing The Efficiency of Islamic Banks in Malaysia And Indonesia. Buletin Ekonomi Moneter dan Perbankan.

${ }^{15}$ Karim, Adiwarman A. dan Adi Zakaria Affif. 2005. Islamic Banking Consumer Behaviour in Indonesia: A Qualitative Approach. 6th Conference on Islamic Economics and Financial.

${ }^{16}$ Othman, Absul Qawi dan Lynn Owen. 2008. Adopting and Measuring Customer Service Quality (SQ) In Islamics Banks: A Case Study In Kuwait Finance House. International Journal of Islamic Financial Services, Vol 3, No.1, page 1-26. 
Vo. 1. No. 1, Juni 2018, 114-134

\begin{tabular}{|c|c|c|c|}
\hline & $\begin{array}{l}\text { Kuwait Finance } \\
\text { House }\end{array}$ & $\begin{array}{l}\text { Alat analisis yang } \\
\text { digunakan adalah } \\
\text { Analisis Faktor }\end{array}$ & \\
\hline $\begin{array}{l}\text { Yaumidin, } \\
\text { Umi Karomah } \\
(2007)\end{array}$ & $\begin{array}{l}\text { Efficiency In } \\
\text { Islamic } \\
\text { Banking: A } \\
\text { Non-Parametic } \\
\text { Approach }\end{array}$ & 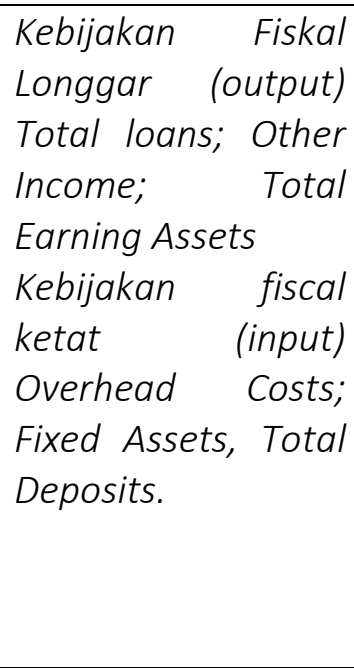 & $\begin{array}{l}\text { Bank-bank Islam di Asia } \\
\text { Tenggara sedikit lebih } \\
\text { efisien dibandingkan } \\
\text { bank-bank Islam di } \\
\text { Timur Tengah. } \\
\text { Bank-bank Islam } \\
\text { tergantung pada sistem } \\
\text { keuangan dan } \\
\text { peraturan } \\
\text { karakteristik perbedaan } \\
\text { risikorang } \\
\text { berkonsekuensi yang } \\
\text { meentukan efisiensi. }\end{array}$ \\
\hline $\begin{array}{l}\text { Ascarya } \\
\text { Diana } \\
\text { Yumanita } \\
\text { (2008) }\end{array}$ & $\begin{array}{l}\text { Comparing The } \\
\text { Efficiency of } \\
\text { Islamic Banks } \\
\text { in Malaysia } \\
\text { and Indonesia }\end{array}$ & $\begin{array}{l}\text { Input } \\
\text { Intermediation } \\
\text { approach : staff } \\
\text { cost; fiixed assets; } \\
\text { total deposits. } \\
\text { Production } \\
\text { approach interest } \\
\text { costs; staff cost, } \\
\text { operational costs. } \\
\text { Assets approach; } \\
\text { staff costs to total } \\
\text { assets; interest } \\
\text { costs to total } \\
\text { assets; other costs } \\
\text { to total assets. } \\
\text { Output lit } \\
\text { Intermediation } \\
\text { total loans; ther } \\
\text { income; liquid } \\
\text { assets Alat analisis DEA }\end{array}$ & $\begin{array}{l}\text { Bank Islam di Indonesia } \\
\text { lebih efisiensi dari bank } \\
\text { Islam di Malaysia dalam } \\
\text { hal financial technical. }\end{array}$ \\
\hline $\begin{array}{l}\text { Ali Polat, } \\
\text { Mehmet }\end{array}$ & $\begin{array}{l}\text { Understanding } \\
\text { Islamic Bank }\end{array}$ & $\begin{array}{l}\text { Kualitas bank, } \\
\text { kecepatan }\end{array}$ & $\begin{array}{l}\text { Kualitas bank, } \\
\text { kecepatan transaksi dan }\end{array}$ \\
\hline
\end{tabular}


Vo. 1. No. 1, Juni 2018, 114-134

\begin{tabular}{|c|c|c|c|}
\hline $\begin{array}{l}\text { Yesilyaprak } \\
\text { dan Raci Kaya } \\
(2014)^{17}\end{array}$ & $\begin{array}{l}\text { Selection of } \\
\text { Customers: A } \\
\text { Field Research } \\
\text { from Turkish } \\
\text { Participation } \\
\text { Banks }\end{array}$ & $\begin{array}{l}\text { transaksi dan } \\
\text { aturan serta } \\
\text { keputusan nasabah } \\
\text { memilih } \\
\text { syari'ah } \\
\text { Alat : Principal } \\
\text { Component } \\
\text { Analysis }\end{array}$ & $\begin{array}{lr}\text { aturan } & \text { bank } \\
\text { berpengaruh signifikan } \\
\text { terhadap keputusna } \\
\text { ansabah memilih bank } \\
\text { syari'ah. }\end{array}$ \\
\hline
\end{tabular}

Sumber: berbagai penelitian

\section{Metode Penelitian}

Penelitian ini adalah explanatory research yang bertujuan untuk menjelaskan hubungan-hubungan antara satu variabel dengan variabel lainnya. Penelitian ini termasuk dalam confirmatory research karena tujuannya menjelaskan hubungan kausal antar variabel melalui pengujian hipotesis ${ }^{18}$. Pengambilan data penelitian dilakukan dengan cara penyebaran kuesioner yang datanya dikumpulkan dari sampel atas populasi untuk mewakili seluruh populasi.

Populasi penelitian ini adalah nasabah bank syari'ah, nasabah bank konvensional di wilayah Bangka Belitung. Jumlah sampel bank syari'ah sebanyak 50 orang dan sampel nasabah bank syari'ah dan bank konvensional sebanyak 50 orang. Total sampel 100 orang.

Variabel-variabel yang digunakan di dalam penelitian ini meliputi:

a. Sifat pribadi adalah ciri-ciri kepribadian yang dimiliki konsumen yang mempengaruhi keputusan memilih bank syari'ah yang meliputi pendidikan, umur, dan jenis kelamin, kedudukan sosial, agama, keterbukaan ide. Kebutuhan nyata terhadap perbankan dengan indikator pendapatan, jenis pekerjaan, aksebilitas wilayah, dan pengeluaran rumah tangga.

b. Sosial adalah faktor-faktor sosial yang mempengaruhi keputusan nasabah memiliki bank syari'ah yang meliputi indikator kepercayaan, harapan

\footnotetext{
${ }^{17}$ Polat, Ali, Mehmet Yesilyaprak dan Raci Kaya. 2014. Understanding Islamic Bank Selection of Customers: A Field Research from Turkish Participation Banks. International Journal of Financial Research. Vol. 5 No.4.

${ }^{18}$ Dimyati, Mohamad. 2009. Analisis SEM Dalam Uji Pengaruh Beberapa Variabel Terhadap Loyalitas Kajian Berbasis Riset Pada Debitur Kredit Usaha Kecil. Edisi Pertama. Jakarta: Mitra Wacana Media
} 
Vo. 1. No. 1, Juni 2018, 114-134

erhadap bank, nilai/ sikap terhadap penyimpangan dengan indikator kehadiran bank umum, kehadiran bank syari'ah, toleransi terhadap penyimpangan dengan indikator kehadiran bank umum, kehadiran bank syari'ah, kesatuan komunikasi dengan indikator aksebilitas terhadap media massa.

\section{Hasil Penelitian}

1. Hasil Uji instrumen

a. Uji Validitas

Uji validitas menunjukkan kemampuan instrument penelitian, mengukur apa yang hendak diukur dan dapat mengungkapkan data dari variabel yang diteliti secara tepat Validitas ditentukan dengan mengkorelasikan skor masingmasing item terhadap skor total masing-masing item. Hasil uji validitas disajikan pada Tabel 2 berikut.

Tabel 2

Hasil Uji Validitas Kuesioner

\begin{tabular}{|c|c|c|c|c|}
\hline Variabel & $\begin{array}{c}\text { Item } \\
\text { Pertanyaan }\end{array}$ & $r$ hitung & r tabel & Keterangan \\
\hline \multirow{11}{*}{ Sifat Pribadi } & SP.1 & 0,601 & \multirow{15}{*}{0,163} & Valid \\
\hline & SP. 2 & 0,646 & & Valid \\
\hline & SP.3 & 0,507 & & Valid \\
\hline & SP.4 & 0,515 & & Valid \\
\hline & SP. 5 & 0,471 & & Valid \\
\hline & SP. 6 & 0,403 & & Valid \\
\hline & SP.7 & 0,421 & & Valid \\
\hline & SP.8 & 0,497 & & Valid \\
\hline & SP.9 & 0,378 & & Valid \\
\hline & SP.10 & 0,851 & & Valid \\
\hline & SP.11 & 0,833 & & Valid \\
\hline \multirow{4}{*}{ Sistem Sosial } & SS.1 & 0,256 & & Valid \\
\hline & SS. 2 & 0,186 & & Valid \\
\hline & SS. 3 & 0,189 & & Valid \\
\hline & SS.4 & 0,171 & & Valid \\
\hline
\end{tabular}


\begin{tabular}{|l|l|l|l|l|} 
& SS.5 & 0,209 & Valid \\
\hline
\end{tabular}

Sumber : Data primer diolah tahun 2018

Hasil uji validitas menunjukkan bahwa seluruh item valid karena memiliki $r$ hitung $>r$ tabel yaitu 0,163 sehingga seluruh instrumen dapat digunakan dalam penelitian.

b. Uji Reliabilitas

Uji realibitas menggunakan standardized item alpha. Setelah diperoleh nilai $\alpha$, selanjutnya membandingkan nilai tersebut dengan angka kritis reliabilitas sebesar 0,60 sehingga dapat dikatakan reliabel jika nilai $\alpha$ lebih besar 0,6019 Hasil pengujian reliabilitas ditunjukkan Tabel 3 berikut.

Tabel 3

Reliabilitas Instrumen Penelitian

\begin{tabular}{ccccc}
\hline No & Variabel & Nilai $\alpha$ & Reliabilitas & Keterangan \\
\hline 1 & Sifat Pribadi & 0,60 & 0,997 & Reliabel \\
\hline 2 & Sistem Sosial & 0,60 & 0,887 & Reliabel \\
\hline
\end{tabular}

Sumber : Data primer diolah tahun 2018

Berdasarkan Tabel 3 terlihat bahwa semua nilai $\alpha$ lebih besar dari nilai angka kritis reliabilitas sebesar 0,60, sehingga semua butir pertanyaan dapat dipercaya dan dapat digunakan untuk penelitian selanjutnya.

\section{Analisis Faktor (Confimatory Faktor Analysis)}

CFA digunakan untuk mereduksi variabel yang tidak bisa terukur. Kriteria analisis faktor (Confimatory Faktor Analysis) adalah valid jika nilai KMO > 0,5 dan Barlett's Test dengan signifikansi $<0,05$. Hasil analisis faktor dijelaskan pada Tabel 4 berikut.

\section{Tabel 4}

${ }^{19}$ Ghozali, Imam. 2002. Aplikasi Analisis Multivariate dengan Program SPSS. Edisi 4. Semarang: Badan Penerbit-Undip.

${ }^{15}$ Dimyati, Mohamad. 2009. Analisis SEM Dalam Uji Pengaruh Beberapa Variabel Terhadap Loyalitas Kajian Berbasis Riset Pada Debitur Kredit Usaha Kecil. Edisi Pertama. Jakarta: Mitra Wacana Media 
Hasil Uji Validitas Data

\begin{tabular}{ccccc}
\hline No & Variabel & Nilai KMO & Barlett's Test & Keterangan \\
\hline 1 & Sifat Pribadi & 0,952 & 0,000 & Valid \\
\hline 2 & Sistem Sosial & 0,523 & 0,000 & Valid \\
\hline
\end{tabular}

Sumber : Data primer diolah tahun 2018

Berdasarkan hasil perhitungan nilai $\mathrm{KMO}$ menyatakan nilai $\mathrm{KMO}>0,5$ dan Barlett's Test $<0,05$. Oleh karena itu seluruh item pertanyaan dinyatakan valid.

\section{Hasil Analisis Regresi Logistik}

Penelitian ini mengidentifikasi karakteristik nasabah yang terdiri dari spiritual market (Moslems) dan Floating Market. Kategori nasabah yang digolongkan menjadi dua kategori, spiritual market (Moslems) adalah nasabah yang hanya mau berhubungan dengan lembaga keuangan/bank syari'ah saja; Floating Market adalah nasabah yang mau berhubungan dengan bank syari'ah dan juga bank konvensional. Penelitian ini menggunakan pendekatan Logistic Regression, dimana variabel terikatnya merupakan data kualitatif yang berupa data nominal dalam bentuk dummy. Dummy dari pada variabel terikat ini adalah ya (bank syari'ah dan bank konvensional) atau tidak (bank syari'ah). Pemberian kode dummy dengan menggunakan kategori yang dinyatakan dengan angka 1 yang disebut included group untuk kategori melakukan pemilihan dan diberi nilai 0 (nol) yang disebut excluded group untuk kategori memilih bank syari'ah.

a. Pengujian Model

Untuk menguji bahwa model (yang sudah memasukkan variabel independennya) sudah sesuai (fit) dengan data, maka perlu dilihat dari tabel Omnibus Tests of Model Coefficients, tabel Model Summary, tabel Hosmer and Lemeshow Test dan Classification Tabel

1) Tabel Omnibus Tests of Model Coefficients

Tabel Omnibus Tests of Model Coefficients dapat digunakan untuk menilai apakah model yang akan dimasukkan sudah fit dengan data dengan melihat 3 langkah yang diambil yaitu Step, Block dan Model.

\section{Tabel 5}

Omnibus Tests of Model Coefficients

Omnibus Tests of Model Coefficients 


\begin{tabular}{|ll|r|r|r|}
\hline & & Chi-square & Df & \multicolumn{1}{|c|}{ Sig. } \\
\hline Step 1 & Step & 33,975 & 5 &, 000 \\
& Block & 33,975 & 5 &, 000 \\
& Model & 33,975 & 5 &, 000 \\
\hline
\end{tabular}

Sumber : Data primer diolah tahun 2018

Berdasarkan tabel di atas, diperoleh nilai $\chi^{2}$ - hitung sebesar 33,975 dengan derajat bebas $=4$, sedangkan nilai $\chi^{2}$-tabel dengan derajat bebas $=5$ adalah sebesar 9,48, berarti $\chi^{2}$-hitung $>\chi^{2}$-tabel $(33,975>9,48)$. Dengan demikian model sudah fit dengan data dan analisa dapat dilanjutkan.

\section{2) Tabel Model Fit}

Menilai keseluruhan model menunjukkan model logistik yang lebih baik atau sebaliknya antara model logistik pada Block number $=0$ dan Block number $=$ 1. Hal ini didasarkan pada nilai -2 Log Likehood. Berdasarkan Lampiran 6, diperoleh nilai -2 Log Likehood pada Block number $=0$ sebesar 233,820 sedangkan pada Block number $=1$ sebesar 241,548. Penurunan ini menunjukkan model logistik yang lebih baik, artinya model logistik pada Block number $=1$ lebih baik dari Block number $=0$.

Penentuan model yang baru adalah lebih baik dari model awal ditunjukkan oleh penurunan nilai -2 Log Likelihood dari model awal. Nilai Cox \& Snell $R$ Square merupakan ukuran yang mencoba meniru ukuran $R^{2}$ pada multiple regression yang didasarkan pada teknik estimasi likelihood dengan nilai maksimum kurang dari 1 (satu), sedangkan untuk nilai Nagelkerke $R^{2}$ dapat disamakan dengan nilai Adjusted $R^{2}$ pada multiple regression. Adapun hasil iteration history dan model summary disajikan pada tabel berikut.

\section{Tabel 6}

\section{Iteration History Dan Model Summary}

Model Summary

\begin{tabular}{|l|r|r|r|}
\hline Step & -2 Log likelihood & Cox \& Snell R Square & Nagelkerke R Square \\
\hline 1 & $241,548^{\mathrm{a}}$ &, 199 &, 261 \\
\hline
\end{tabular}

Sumber : Data primer diolah tahun 2018

Berdasarkan Tabel 6 menunjukkan nilai -2 Log Likelihood sebesar 241,548 sedangkan -2 Log Likelihood awalnya sebesar 211,120, berarti terjadi penurunan 
Jurnal Ilmiah Sustainable

Vo. 1. No. 1, Juni 2018, 114-134

nilai -2 Log Likelihood dan penurunan nilai -2 Log Likelihood ini menunjukkan bahwa model yang baru adalah lebih baik, sehingga analisis dapat dilanjutkan.

3) Tabel Hosmer and Lemeshow Test

Untuk melihat bahwa model yang dibuat adalah baik dan fit dengan data maka dilihat pada nilai statistik Hosmer and Lemeshow Test Goodness-of-fit. Adapun hasil Hosmer and Lemeshow Test Goodness-of-fit disajikan pada Tabel 7.

\section{Tabel 7}

Hosmer and Lemeshow Test Goodness-of-fit

Hosmer and Lemeshow Test

\begin{tabular}{|l|r|r|rr|}
\hline Step & Chi-square & df & \multicolumn{2}{|c|}{ Sig. } \\
\hline 1 & 7,225 & & 8 &, 434 \\
\hline
\end{tabular}

Sumber : Data primer diolah tahun 2018

Berdasarkan Tabel 7, diperoleh nilai Hosmer and Lemeshow Test Goodness-of-fit sebesar 7,225 dengan nilai signifikansi 0,434 ( $p>0,05)$, sehingga dapat disimpulkan bahwa model dapat diterima. Hasil analisis regresi logistik disajikan pada Tabel 8 berikut.

Tabel 8

Analisis Regresi Logistik

Variables in the Equation

\begin{tabular}{|c|c|c|c|c|c|c|c|c|c|}
\hline & \multirow[t]{2}{*}{$B$} & \multirow[t]{2}{*}{ S.E. } & \multirow[t]{2}{*}{ Wald } & \multirow[t]{2}{*}{$d f$} & \multirow[t]{2}{*}{ Sig. } & \multirow[t]{2}{*}{$\operatorname{Exp}(B)$} & \multicolumn{2}{|c|}{$\begin{array}{c}\text { 95\% C.I.for } \\
\operatorname{EXP}(B)\end{array}$} \\
\hline & & & & & & & & Lower & Upper \\
\hline \multirow{5}{*}{$\begin{array}{l}\text { Step } \\
1^{a}\end{array}$} & $\mathrm{Jk}$ & 0,211 & 0,249 & 1,361 & 1 & 0,175 & 1,211 & 0,921 & 2,227 \\
\hline & Usia & 0,216 & 0,151 & 4,390 & 1 & 0,023 & 1,452 & 1,021 & 1,843 \\
\hline & Status & $-0,210$ & 0,113 & 0,953 & 1 & 0,432 & 0,877 & 0,718 & 1,117 \\
\hline & $\begin{array}{l}\text { Sifat } \\
\text { Pribadi }\end{array}$ & $-0,153$ & 0,252 & 4,008 & 1 & 0,022 & 1,368 & 0,106 & 1,272 \\
\hline & $\begin{array}{l}\text { Sistem } \\
\text { Sosial }\end{array}$ & $-0,133$ & 0,253 & 0,085 & 1 & 0,871 & 0,918 & 0,566 & 1,525 \\
\hline
\end{tabular}

a. Variable(s) entered on step 1: Jk, Usia, Status, Sifat Pribadi, Sistem Sosial. 


\section{Jurnal Ilmiah Sustainable}

Vo. 1. No. 1, Juni 2018, 114-134

Hasil perhitungan analisis regresi logistik mengidentifikasi karakteristik spiritual market (Moslems) dan Floating Market. Fungsi regresi logit tersebut dapat dituliskan dalam fungsi linear sebagai berikut.

$$
\hat{Y}_{t}=1,211 S P_{t}+1,452 X_{2 t}+0,877 X_{3 t}+1,368 X_{4 t}+0,918 X_{5 t}+e_{t}
$$

Berdasarkan persamaan tersebut dan tabel maka dapat dijelaskan sebagai berikut:

a. Jenis kelamin memiliki koefisien regresi sebesar 1,211 dan wald signifikansi sebesar 0,175. Hal ini membuktikan hipotesis satu (H1) ditolak karena nilai signifikansi > 0,05 (5\%), artinya jika variabel usia, status, sifat pribadi dan sistem sosial konstan maka jenis kelamin tidak berpengaruh terhadap keputusan memilih bank syari'ah dan bank konvensional.

b. Usia memiliki koefisien regresi sebesar 1,452 dan wald signifikansi sebesar 0,023 . Hal ini membuktikan hipotesis dua $(\mathrm{H} 2)$ diterima karena nilai signifikansi < 0,05 (5\%) artinya jika variabel jenis kelamin, status, sifat pribadi dan sistem sosial konstan maka setiap kenaikan usia sebesar satu tahun maka berpengaruh terhadap keputusan memilih bank syari'ah dan bank konvensional.

c. Status pekerjaan memiliki koefisien regresi sebesar 0,877 dan wald signifikansi sebesar 0,432. Hal ini berarti hipotesis tiga (H3) ditolak karena nilai signifikansi > 0,05 (5\%) maka jika variabel jenis kelamin, sifat pribadi dan sistem sosial konstan maka status pekerjaan tidak berpengaruh terhadap keputusan memilih bank syari'ah dan bank konvensional.

d. Sifat pribadi memiliki koefisien regresi sebesar 1,368 dan wald signifikansi sebesar 0,032. Hal ini berarti hipotesis tiga (H3) diterima karena nilai signifikansi $<0,05(5 \%)$ berarti variabel jenis kelamin, sifat pribadi dan sistem sosial konstan maka sifat pribadi berpengaruh signifikan terhadap keputusan memilih bank syari'ah dan bank konvensional.

e. Sistem sosial memiliki koefisien regresi sebesar 0,918 dan wald signifikansi sebesar 0,771. Hal ini berarti hipotesis lima (H5) diterima karena nilai signifikansi > 0,05 (5\%) artinya menunjukkan bahwa jika variabel jenis kelamin, sifat pribadi dan sistem sosial konstan maka sistem sosial tidak berpengaruh terhadap keputusan memilih bank syari'ah dan bank konvensional.

4) Likelihood Ratio (LR) Test 
Vo. 1. No. 1, Juni 2018, 114-134

Untuk menguji hipotesis bahwa semua koefisien arah secara simultan atau bersama-sama, signifikansi terbesar $0(=$ nol) sejenis uji $\mathrm{F}$ dalam model logistik adalah Likehood Ratio (LR) Statistic. Dalam hipotesis seperti ini, LR statistic mengikuti distribusi Khikuadrat (chi-square) dengan $\mathrm{df}=$ "degress of fridom" sebanyak variabel bebas.

Ukuran LR statistic sebesar 33,975 dengan tingkat signifikansi sama dengan nol maka berarti hipotesis terbukti. Hal ini menunjukkan bahwa secara simultan semua variabel jenis kelamin, usia, status, sifat pribadi dan sistem sosial berpengaruh signifikan terhadap keputusan memilih bank syari'ah dan bank konvensional secara simultan.

\section{5) Koefisien Determinasi}

Koefisien ini digunakan untuk mengetahui besarnya sumbangan variabel independen terhadap variabel terikat yaitu keputusan memilih bank syari'ah dan bank konvensional. Ukuran $\mathrm{R}^{2}$ pada metode logistik berdasarkan nilai Nagelkerke $R$ Square yang didasarkan pada tehnik estimasi likelihood dengan nilai yang bervariasi dari nol (0) sampai 1 (satu). Berdasarkan nilai Cox dan Snell $R$ square sebesar 0,199 atau 19,9\% dan Nagelkerke $R$ Square sebesar 0,261 atau $26,1 \%$ berarti variabilitas variabel jenis kelamin, usia, status, sifat pribadi dan sistem sosial sebesar $26,1 \%$ sedangkan sisanya dipengaruhi oleh variabel di luar penelitian sebesar $73,9 \%$.

6) Ketepatan Prediksi Model

Ketepatan prediksi dilakukan pada keputusan memilih bank syari'ah dan bank konvensional dapat dilihat pada Tabel 9.

Tabel 9. Uji Ketepatan Prediksi Classification Table ${ }^{a}$

\begin{tabular}{|c|c|c|c|}
\hline \multirow[t]{3}{*}{ Observed } & \multicolumn{3}{|c|}{ Predicted } \\
\hline & \multicolumn{2}{|r|}{$\bar{Y}$} & \\
\hline & $\begin{array}{c}\text { Bank } \\
\text { Syariah }\end{array}$ & $\begin{array}{c}\text { Bank Syariah } \\
\text { dan Bank } \\
\text { Konvensional }\end{array}$ & $\begin{array}{c}\text { Percentage } \\
\text { Correct }\end{array}$ \\
\hline
\end{tabular}




\begin{tabular}{|c|c|c|c|c|}
\hline \multirow[t]{3}{*}{ Step 1} & Bank Syariah & 3 & 45 & 5,1 \\
\hline & $\begin{array}{l}\text { Bank Syariah } \\
\text { dan Bank } \\
\text { Konvensiona }\end{array}$ & 1 & 55 & 89,4 \\
\hline & Overall Percentage & & & 69,0 \\
\hline
\end{tabular}

a. The cut value is , 500

Tabel 9 merupakan dua nilai prediksi dari variabel dependen dalam hal ini keputusan memilih (1) dan memilih bank syari'ah (0), sedangkan pada baris menunjukkan nilai observasi yang sesungguhnya dari variabel dependen keputusan memilih (1) dan memilih bank syari'ah (0). Hasil Tabel 9 menunjukkan bahwa pada kolom, prediksi konsumen tentang keputusan keputusan memilih sebanyak 55 konsumen sedangkan observasi sebesar 100 konsumen atau memiliki ketepatan prediksi sebesar 89,4\%. Sedangkan konsumen yang melakukan keputusan memilih bank syari'ah diprediksikan sebanyak 45 konsumen dari observasi memiliki ketepatan prediksi sebesar 5,1\%. Hasil ketepatan prediksi secara keseluruhan adalah sebesar $69 \%$.

\section{E. Pembahasan}

Responden penelitian ini masyarakat yang memutuskan memilih bank syari'ah dan bank umum (konvensional). Total responden penelitian ini adalah 100 responden. Responden sejumlah tersebut diambil wilayah Bangka Belitung. Berdasarkan jumlah tersebut sebanyak $69,2 \%$ responden berjenis kelamin laki-laki dan 30,8\% berjenis kelamin perempuan.

Usia dan pengalaman hidup seseorang merupakan faktor penting yang dapat mempengaruhi persepsi. Oleh karena itu penelitian ini berusaha mendapatkan data mengenai usia responden. Berdasarkan kategori usia ini, mayoritas responden berada pada kelompok usia produktif (17 hingga 46 tahun) yakni sebesar 74\%. Dalam penelitian ini, peneliti telah berusaha untuk melaksanakan pengambilan sampel secara random, dengan harapan dapat dilibatkan responden dari berbagai agama/ kepercayaan yang berbeda. Sebanyak 100 responden bersedia menjawab pertanyaan tentang agama/kepercayaan mereka, dan diketahui bahwa mayoritas responden adalah umat Islam (94,6\%). Berdasarkan tingkat pendidikannya, mayoritas responden 86\% berpendidikan SMA dan Perguruan Tinggi. Besarnya jumlah responden yang 


\section{Jurnal Ilmiah Sustainable}

Vo. 1. No. 1, Juni 2018, 114-134

menyatakan pernah kuliah di Perguruan Tinggi atau sudah lulus Program D3, S1 atau S2 barang kali akan membantu menjawab pertanyaan-pertanyaan dalam kuesioner penelitian ini secara akurat.

Berdasarkan penghasilan rata-rata perbulan, respoden penelitian ini mayoritas adalah anggota masyarakat yang termasuk berpenghasilan "rendah" dan "menengah". Berdasarkan data yang disajikan berikut ini, dapat dilihat bahwa mayoritas responden berpenghasilan kurang dari Rp1.000,000 perbulan. Untuk ukuran biaya hidup di Bangka Belitung untuk mereka yang sudah berkeluarga dan dengan memperhatikan mahalnya biaya hidup saat ini, penghasilan sebesar itu termasuk kategori "cukup". Berdasarkan besarnya penghasilan dan konsumsi sebagaimana disebutkan sebelumnya, penelitian ini menemukan bahwa $48 \%$ responden menyatakan mampu menabung secara rutin. Umumnya mereka menabung di Bank Konvensional dan Syari'ah. Hanya 2,4\% responden yang menyatakan pernah menabung di Bank Syari'ah. Tingkat pemahaman responden terhadap bank Syariah juga sangat minim,yaitu hanya 9,7\% responden yang menyatakan memahami produk-produk Bank Syari'ah.

Responden yang menjadi nasabah bank syari'ah memiliki tingkat pendidikan yang jauh lebih baik dari pada responden non nasabah bank syari'ah. Ini merupakan fakta yang agak mengagetkan karena umumnya diyakini bahwa mereka yang berhubungan dengan bank syari'ah lebih banyak didasarkan pada ikatan emosional semata. Tetapi dengan melihat tingkat pendidikan yang cukup baik, hampir $70 \%$ di antaranya telah mengenyam pendidikan tinggi, maka fenomena tersebut lebih tepat diartikan sebagai tingkat kesadaran mereka untuk menerapkan ajaran agama secara lengkap. Hal ini sebuah cerminan dimana sebenarnya masih ada orang Islam diantara kita yangingin melaksanakan ajaran Islam secara lengkap.

Bagi responden yang belum menjadi nasabah bank umum tetapi tertarik dengan bank syari' ah, ternyata sebagian besar diantaranya tidak mengenal bank syari'ah beserta produk-produknya. Hanya sebesar $13 \%$ diantara mereka yang paham dengan bank syari'ah. Hal ini menunjukkan bahwa preferensi mereka terhadap bank syari'ah sebenarnya masih belum utuh. Ketertarikan mereka terhadap bank syari'ah barang kali disebabkan oleh konsep bank syari'ah yang humanis dan adil setelah mendapat penjelasan dari enumerator lapangan.

Berdasarkan gambaran tersebut dapat disimpulkan bahwa masyarakat 


\section{Jurnal Ilmiah Sustainable}

Vo. 1. No. 1, Juni 2018, 114-134

masih awam terhadap keberadaan bank syari'ah khususnya berkaitan dengan prinsip-prinsip maupun produk-produk bank syari'ah. Sosialisasi dan penyebaran informasi mengenai keberadaan, prinsip, dan tata kerja bank syari'ah kepada masyarakat perlu mendapat perhatian yang cukup besar. Keterbatasan pengenalan masyarakat menyebabkan masih relatif rendahnya preferensi masyarakat. Berdasarkan karakteristik budayanya, konsumen yang memiliki preferensi terhadap bank syari'ah memiliki beberapa karakter. Karakter nasabah adalah orang humanis dan sekaligus memiliki sifat dinamis. Di samping itu, mereka mendambakan kehidupan yang lebih modern, bergaya hidup materialis, memiliki sikap dan keyakinan yang jelas, selalu memperhatikan status dan peran mereka dalam segala tindakan, dan berusaha untuk mempraktekkan ajaran agama dalam kehidupan sehari-hari.

Hasil pengujian menjelaskan bahwa setiap perbedaan jenis kelamin tidak berpengaruh terhadap keputusan memilih bank syari'ah dan bank konvensional. Faktor usia berpengaruh terhadap keputusan memilih. Status pekerjaan tidak berpengaruh terhadap keputusan memilih bank syari'ah dan bank konvensional. Setiap perubahan sifat pribadi berpengaruh negatif dan signifikan terhadap keputusan memilih bank syari'ah atau konvensional. Variabel jenis kelamin, sifat pribadi dan sistem sosial konstan maka setiap kenaikan sistem sosial tidak berpengaruh terhadap keputusan memilih bank syari'ah atau konvensional

Karakter budaya masyarakat Bangka Belitung membawa implikasi bagi pengembangan bank syari'ah. Hal itu dimaksudkan keberadaan bank syari'ah bisa diterima oleh masyarakat, maka bank syari'ah harus memperhatikan perilaku budaya dari calon nasabah potensialnya. Misalnya, nasabah potensialnya adalah orang-orang yang berusaha mempraktekkan ajaran agama dalam kehidupan sehari-hari, tetapi pilihan mereka terhadap bank bukan semata-mata karena label agama.

Secara umum masyarakat yang berpreferensi pada bank konvensional mirip yang ditemukan pada masyarakat yang berpreferensi pada bank syari'ah. Artinya, bahwa masyarakat sebetulnya memiliki sikap yang rasional dalam menjatuhkan pilihan pada bank konvensional. Beberapa faktor memang terkait dengan aspek agama dan nilai kemanusiaan. Hal ini wajar karena seluruh responden adalah masyarakat yang beragama (mayoritas beragama Islam). Namun pilihan mereka terhadap bank konvensional dengan faktor agama dan 


\section{Jurnal Ilmiah Sustainable}

Vo. 1. No. 1, Juni 2018, 114-134

moral mungkin disebabkan oleh beberapa hal, yaitu bank konvensional tidak bertentangan dengan ajaran agama dan moral; tidak tahu bahwa operasional bank konvensional bertentangan dengan ajaran agama; tahu bahwa bank konvensional bertentangan dengan ajaran agama,tetapi tidak ada pilihan lain kecuali bank konvensional dan Tidak mengenal bank syari'ah. Faktor lainnya menyangkut sifat pribadi dan sosial merupakan konsekuensi logis dari karakteristik masyarakat yang rasional. Artinya pilihan bank konvensional tidak terlepas kalkulasi untung dan rugi. Sementara faktor budaya merupakan karakteristik lain yang juga mempunyai peran bagaimana masyarakat yang bersangkutan mempersepsikan dan memilih bank konvensional sebagai pilihan yang tepat untuk keperluan kehidupannya.

\section{F. Penutup}

Berdasarkan hasil penelitian maka dapat bahwa setiap perbedaan gender maka tidak berpengaruh terhadap keputusan memilih bank syariah dan bank konvensional. Faktor usia berpengaruh terhadap keputusan memilih bank syariah dan bank konvensional. Status pekerjaan tidak berpengaruh terhadap keputusan memilih bank syari'ah dan bank konvensional. Setiap perubahan sifat pribadi berpengaruh negatif dan signifikan terhadap keputusan memilih bank syariah dan bank konvensional.. Variabel jenis kelamin, sifat pribadi dan sistem sosial konstan maka setiap kenaikan sistem sosial tidak berpengaruh terhadap keputusan memilih bank syariah dan bank konvensional.

\section{DAFTAR PUSTAKA}

Astutik, Rini Puji.2015. Faktor-faktor Pemilihan Bank Syariah. Jurnal Universitas Muhammadyah Jember. Vol. 5.No.2

Bank Indonesia. 2015. Outlook Perbankan Syariah 2015.

Dimyati, Mohamad. 2009. Analisis SEM Dalam Uji Pengaruh Beberapa Variabel Terhadap Loyalitas Kajian Berbasis Riset Pada Debitur Kredit Usaha Kecil. Edisi Pertama. Jakarta: Mitra Wacana Media.

Ghafur, Muhammad. 2007. Potret Perbankan Syariah Terkini (Kajian Kritis Perkembangan Perbankan Syariah). Yogyakarta: Biruni Press.

Ghozali, Imam. 2002. Aplikasi Analisis Multivariate dengan Program SPSS. Edisi 4. Semarang: Badan Penerbit-Undip. 


\section{Jurnal Ilmiah Sustainable}

Vo. 1. No. 1, Juni 2018, 114-134

Karim, Adiwarman A. dan Adi Zakaria Affif. 2005. Islamic Banking Consumer Behaviour in Indonesia: A Qualitative Approach. 6th Conference on Islamic Economics and Finance.

Othman, Absul Qawi dan Lynn Owen. 2008. Adopting and Measuring Customer Service Quality (SQ) In Islamics Banks: A Case Study In Kuwait Finance House. International Journal of Islamic Financial Services, Vol 3, No.1, page $1-26$.

Polat, Ali, Mehmet Yesilyaprak dan Raci Kaya. 2014. Understanding Islamic Bank Selection of Customers: A Field Research from Turkish Participation Banks. International Journal of Financial Research, Vol. 5 No. 4.

Rivai, Veithzal dan Arviyan Arifin. 2010. Islamic Banking: Sebuah Teori, Konsep, Dan Aplikasi. Jakarta: Bumi Aksara.

Undang-Undang No. 10 Tahun 1998 Tentang Perbankan.

Wouters, Paul. 2016. Islamic Banking In Turkey, Indonesia And Pakistan A Comparison With Malaysia. www.iefpedia.com. Tanggal akses 2 Agustus 2018.v

Yaumidin, Umi Karomah. 2007. Efficiency In Islamic Banking: A non-Parametric Approach, Buletin Ekonomi Moneter dan Perbankan.

Yumanita, Ascaraya Diana. 2008. Comparing The Efficiency of Islamic Banks in Malaysia And Indonesia. Buletin Ekonomi Moneter dan Perbankan.

Yusdani. 2005. Perbankan Syariah Berbasis Floating Market. Millah Vol. IV, No. 2. 